\title{
Henan Cultural Information Resources Sharing Project Persistent Effect Mechanism Research
}

\author{
Weigong CUI ${ }^{1}$, Hui JIAN ${ }^{1}$, Yuan GAN ${ }^{1}$, Zhen ZHANG ${ }^{2}$, Yanfeng LIU $^{3}$ \\ ${ }^{1}$ Henan Provincial Department of Culture, Zhengzhou 450000, China \\ ${ }^{2}$ Zhengzhou University, Zhengzhou 450000, China \\ ${ }^{3}$ Zhengzhou Vcom Science \& Technology Co., Ltd., Zhengzhou 450001, China
}

\begin{abstract}
National Cultural Information Resources Sharing Project is a project which is benefit people and welcomed by people. Since this project started in 2002, it has got great achievements. However, with continuous expansion of the coverage, new problems has coming up. Henan cultural information resources sharing project group not only considering those new problems, but also thinking and exploring a long - term machanism for the project. The group choose resources and management system, as well as forming a guiding principle named guided by government, managed by enterprises, and benefit the people. It works as an intentive mechanism, which will monilize enthusiasm of grass-roots staff, and save the cost of network access for county extensio center through the project operation. With the integration of "data network, voice network and radio/television network", the group did some research and practices on sharing cultural information resources service on television netwoek, internet and $3 \mathrm{G}$ mobile network.
\end{abstract}

Keywords: cultural information resources sharing project, long-term mechanism, IPTV, digital library, cultural industry

\section{河南省文化信息資源共享工程的長效機制研究}

\author{
崔為工 ${ }^{1}$, 翦 輝 ${ }^{1}$, 甘 源 $^{1}$, 張 震 $^{2}$, 劉延鋒 ${ }^{3}$ \\ ${ }^{1}$ 河南省文化廳 鄭州 450000; ${ }^{2}$ 鄭州大學 鄭州 450000; \\ 3 鄭州威科姆科技股份有限公司 鄭州 450001
}

\begin{abstract}
摘 要: 全國文化信息資源共享工程是是深受人民群眾歡迎的惠民工程。項目從 2002 年啟動實施以來 取得了輝煌的成就, 但是隨著覆蓋面的不斷擴大也發現了一些新的問題。河南省文化信息資源共享工 程針對存在的問題的同時對項目發展的長效機制進行了思考和探索，項目組在選擇資源平臺建設、傳 輸網絡建設、播放平臺建設和運行管理體系的同時, 從戰略高度出發, 以政府指導、企業運營、群眾 得實惠為指導方針,形成一套激勵機制調動基層人員工作的積極性運營方案，同時通過項目的運營合作 解決縣支中心網絡接入費用。隨著“三網”融合的實現, 對文化共享工程資源在電視網、互聯網和 $3 \mathrm{G}$ 移動網絡的共享服務也做了一些探討和嘗試。
\end{abstract}

關鍵詞: 文化信息資源共享工程，長效機制，數字圖書館，IPTV 模式，文化產業

\section{1. 引 言}

全國文化資訊資源分享工程 ( 以下簡稱文化資訊 資源分享工程）是新形勢下貫徹落實科學發展觀、構
建公共文化服務體系、惠及千家萬戶的一項重要文化 基礎工程, 是政府提供公益性服務的重大文化專案, 是實現廣大人民群眾基本文化權益的重要途徑, 是解 
決落後地區資訊閉塞, 縮小“數位鴻溝”的有效舉措, 對提高廣大人民群眾的科學文化素質, 推進社會主義 文化大發展大繁榮與建設和諧社會具有重要作用。

河南省文化資訊資源分享工程啟動於 2002 年, 河 南省文化廳針對本省實際, 以點帶面, 全面推進文化 資訊資源分享工程。在項目建設中堅持突出河南省特 色文化資源建設、基層隊伍建設和文化資訊資源分享 工程基層網點覆蓋面建設。工程實施七年來取得了顯 著的成就, 創造性地將文化資訊資源分享工程與黨員 幹部現代遠端教育網共建共用。2007 年 2 月, 中共河 南省委組織部、河南省黨員幹部現代遠端教育試點工 作領導協調小組、河南省文化廳、河南省財政廳聯合 下發了《關於加強全省農村黨員幹部現代遠端教育與 文化資訊資源分享工程資源整合工作的通知》, 正式啟 動了全省農村黨員幹部現代遠端教育與共用工程資源 整合工作, 提出了明確要求, 並做出了全面安排和部 署。文化資訊資源分享工程與農村黨員幹部現代遠端 教育共建共用, 主要包括: 一是整合基礎設施資源。 兩大網路在省級技術平臺上進行資源對接, 實現農村 黨員幹部現代遠端教育資源庫與共用工程資源庫的互 聯互通。農村黨員幹部現代遠端教育終端接收站點和 共用工程基層網點採用“寬頻網路十機頂盒十電視機” 建設模式, 依託聯通的寬頻網路傳輸和播放資源。二 是整合基層網點組織管理資源。在兩大網路基層網點 的組織管理上, 實行統一規劃, 相互協調, 共同管理, 共同服務, 實現人力資源的有效整合。管理人員的培 訓, 由各級遠端辦、文化部門、財政部門共同負責組 織實施, 確保教學管理和組織活動健康有效開展, 形 成了基層網點正常運行和維護的長效機制, 走出了全 國文化資訊資源分享工程的“河南模式”。

\section{2. 實施進展及發現的問題}

河南省文化資訊資源分享工程從開始至今一直受 到省委、省政府的高度重視, 是省委、省政府向全省 人民承諾的十件實事之一。到 2010 年將建成 1 個省分 中心、159 個縣級支中心、 4.8 萬個村級基層服務點, 實現縣縣都有支中心、村村都有基層服務點的全覆蓋 目標, 初步形成一個覆蓋河南全省的文化資訊資源分 享工程服務網路, 全省 6000 萬農村群眾可從中受益。 河南省文化資訊資源分享工程省級分中心現已具備資 源接收、製作、發佈、人員培訓的能力, 並通過 IPTV
網路可以為群眾提供的數位資源總量已達到 $10 \mathrm{~TB}$, 群 眾將可以共用到相當於 1600 萬冊圖書、60000 小時視 頻節目的優秀文化資源，滿足了農民“求知、求富、求 樂”的需求，豐富了農民群眾的精神文化生活，有力的 推進了全省公共文化服務體系建設和新農村建設。與 此同時, 我們也清醒地認識到, 河南省的文化資訊資 源分享工程仍處於起步階段, 還存在許多困難和不 足，在延伸服務的過程中我們發現了以下問題:

1) 部分貧困縣的財政比較困難, 不能按照國家要 求撥付額定配套資金，後期的運行費用（電費、網路 使用費、人員工資等）也無法保障, 影響了共用工程 的可持續發展。

2) 各級公共圖書館、鄉鎮文化站和村級文化大院 技術人才實乏，對伺服器等設備維護有困難比較大。

3）隨著站點數量的不斷增加, 現有的人工上報服 務情沉的管理模式耗費時間長且資料不準確，難以適 應目前專案發展要求。

4）没有健全的激勵機制做保障，致使基層服務點 工作人員積極性不高, 造成了共用工程資源和設備使 用率低，影響了基層文化活動的開展。

5) 河南全省基層網點的數量達到 4.8 萬個左右, 基層服務隊伍的培訓工作開展成為一大難題。

6）由於文化資訊共用工程資源的不斷擴充，農村 黨員幹部現代遠端教育平臺給予的存儲空間已經遠遠 不能滿足專案發展的需求, 需要在農村黨員幹部現代 遠端教育平臺的基礎上擴充文化資訊資源分享工程的 資源存儲及播放平臺。

針對以上幾個問題，河南省文化廳和河南省共用 工程分中心通過積極的調研分析，並進行了思考和探 索，初步形成了一套科學、可行的建設思路。

\section{3. 發展目標}

在“十一五”期間，按照文化部對文化資訊資源分 享工程建設的要求, 河南省文化資訊資源分享工程在 河南省文化廳的領導下，以資源建設為中心，農村基 層服務點為重點, 取得了飛速的發展。為了實現文化 資訊資源分享工程的良性可持續發展，打造文化資訊 資源分享工程的“河南模式”，河南省文化資訊資源分 享工程制定了如下目標：

1) 爭取各級財政的支援, 將文化共用工程各級中 心、基層服務點的運行費用列入財政預算，確保工程 
的日常運行。加強與企業進行合作, 利用文化資訊資 源分享工程的資源優勢與一些企業的業務相結合，互 惠互利，在不增加農村群眾負擔的基礎上開展一些增 值業務, 產生的效益可納入共用工程管理經費, 確保 工程的可持續發展。

2) 通過與電信運營商進行合作, 增強維護管理隊 伍的技術能力。並通過網路培訓系統和業務考核系統 實現工作人員的線上培訓和線上考核, 保證了培訓效 果，降低培訓的難度和成本。

3) 針對文化資訊資源分享工程的需求開發一套 可自主運營和管理的運行系統, 實現業務開展規範化 和資料統計精確化。在省文化廳、市/縣文化局等主管 部門創建運行管理平臺, 在各級中心構建運營平臺, 實現從專案建設管理、行政區劃管理、基層服務站點 管理、業務培訓計畫制訂、培訓情況查詢、活動組織 統計和資源回饋評價的全過程管理。

4) 建立文化資源分享工程的資源建設體系, 整合 國家資源、本地資源和互聯網資源，國家資源實現一 點接收全省共用，本地資源實現省、市、縣特色資源 插入, 全省共用; 並結合數位圖書館建設實現數位圖 書的網路化服務。

5) 通過與黨員幹部現代遠端教育的基礎平臺、傳 輸網路和基層站點建設的結合, 在實現網路站點全覆 蓋的基礎上加快推進共用工程資源的全覆蓋。主要包 括建立文化資訊資源分享工程的資源存儲及播出平 臺, 包括省分中心和市支中心的節目製作、存儲、管 理平臺和市、縣兩級存儲及播出平臺, 並通過 CDN 資源智慧分發與調度手段，實現區域定制化服務。

6) 建設可擴展的應用平臺, 在機頂盒+電視機模式 的基礎上實現投影機+機頂盒、 $\mathrm{PC}+$ 終端點播軟體、 $3 \mathrm{G}$ 手機+資源點播軟體等多種服務模式，滿足城鄉村各種 用戶需求，進一步拓展文化資訊資源工程的服務範圍。

最終要建設成一套河南省文化資訊資源分享工程的 資源建設體系、運行管理體系和運營保障體系, 形成可 運營、可管理、可拓展的“河南模式”文化資源分享工程。

\section{4. 河南省文化資訊資源分享工程的探索}

河南省文化廳結合本省實際情況, 在資訊資源分 享工程的建設中, 以科學發展觀為指導, 緊緊抓住“以 人為本”這一核心, 提出“公益性事業, 社會化管理, 市場化運作”的發展思路, 在系統平臺建設中採用支援 未來 $3 \mathrm{G}$ 移動應用的技術架構, 在運營中大膽創新統
籌兼顧, 規範地植入一些市場元素, 把有能力、有責 任的企業介入到文化資訊資源分享工程的建設運營中 來，通過政府扶持、企業參與、群眾得實惠的原則， 逐步構建河南省農村公共文化服務體系，以確保文化 資訊資源分享工程健康、可持續發展。

\section{1 平臺建設}

首先加強省分中心的建設，建設資源的加工、存 儲、發佈平臺。在共用農村黨員幹部現代遠端教育平 臺節目分發、網路管理、資料獲取、播出管理等系統 的基礎上在各縣區部署資源存儲點播平臺，逐步實現 縣支中心、鄉鎮文化站、街道/社區/村級基層服務網 點的接入。該模式終端接入靈活快捷, 設備操作簡單, 實用性強。並隨著互聯網技術與 $3 \mathrm{G}$ 移動網路的融合, 文化資訊資源分享工程資源在 $3 \mathrm{G}$ 移動網路平臺的應 用將成為未來重要的傳播管道之一。系統平臺網路部 署結構如圖 1 所示，在省分中心建設了獨立的資源接 收、資源加工、資源存儲。

\section{2 運行管理}

河南省文化資訊資源分享工程運行管理系統是文 化資源分享工程的重要組成部分, 運行管理系統採用 B/S 架構, 實現省、市、縣、鄉、村 (社區) 五級管 理網路，完成了從站點開戶、建設管理、行政區劃管 理、業務培訓計畫制訂、培訓情況查詢、文化活動管 理、互動需求回饋、活動資料統計和資源評價的全過 程管理, 能夠讓文化資源分享工程工作從流程上形成 一個閉環，為文化資源工程的推廣和完善提供支撑。 系統模組組成如圖 2 所示:

\section{3 終端服務}

村級基層服務點是基層服務點建設的主要內容。 它用來接收省(市)縣播出平臺播出的文化資訊資源, 供站點使用。同時, 也可通過電視圖文和數位圖書館 的方式，為廣大群眾提供各種網站圖文資訊和圖書閱 讀等服務。河南省文化資訊資源分享工程根據基層服 務特點，有針對性的開發出了“文化共用機頂盒+投影 機”和“PC+PC 資源播放用戶端軟體”的服務模式。可 以廣泛應用於電子閱覽室、農村文化大院、農村文化 活動室等多種應用。可以實現線上下載離線播放、卡 拉 $\mathrm{OK}$ 、數位圖書館等業務，同時還支援各種外接移 動存儲設備，方便流動服務。 


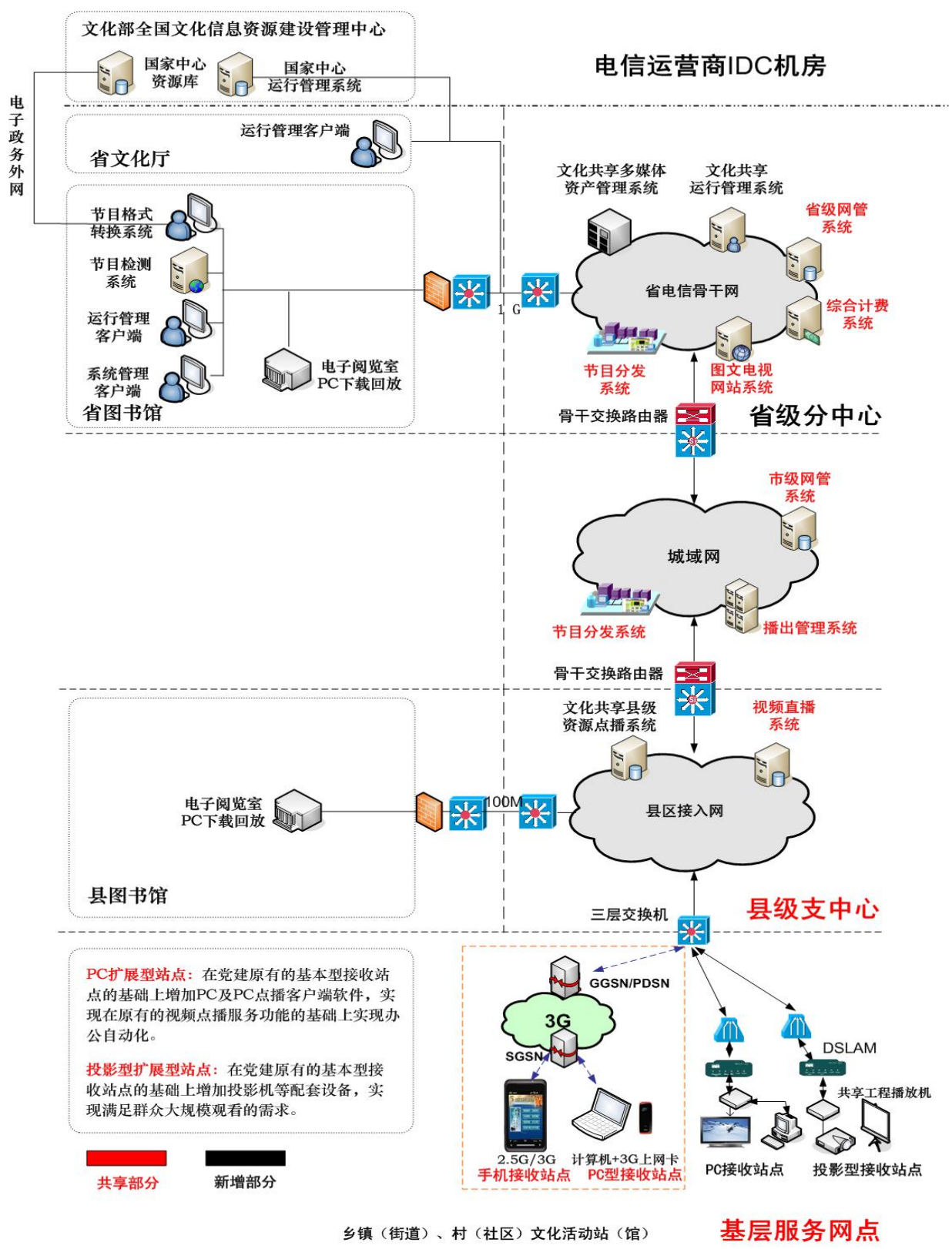

圖 1. 河南省文化信息資源共享工程網絡結構圖

Figure 1. Henan cultural information resources sharing project network structure

\section{4 技術保障}

通過 IPTV 平臺提供文化共用工程技術培訓和考 核為一體的綜合平臺, 可以有效的解決大量基層服務 人員的培訓問題，保證了培訓的效果。同時通過與電 信運營商進行合作，有效的解決了縣級支中心、鄉鎮 文化站、村級基層站點技術力量薄弱問題，保障了系 統的正常運行。

\section{5. 平臺特點}

\section{1 低投入}

可以共用農村黨員幹部現代遠端教育的省級網管 系統、綜合計費系統、圖文網站系統、省級節目分發 系統；市平臺的市級網管系統、市級節目分發系統； 村級終端站點的相關場地、人員和設備，通過資源整 


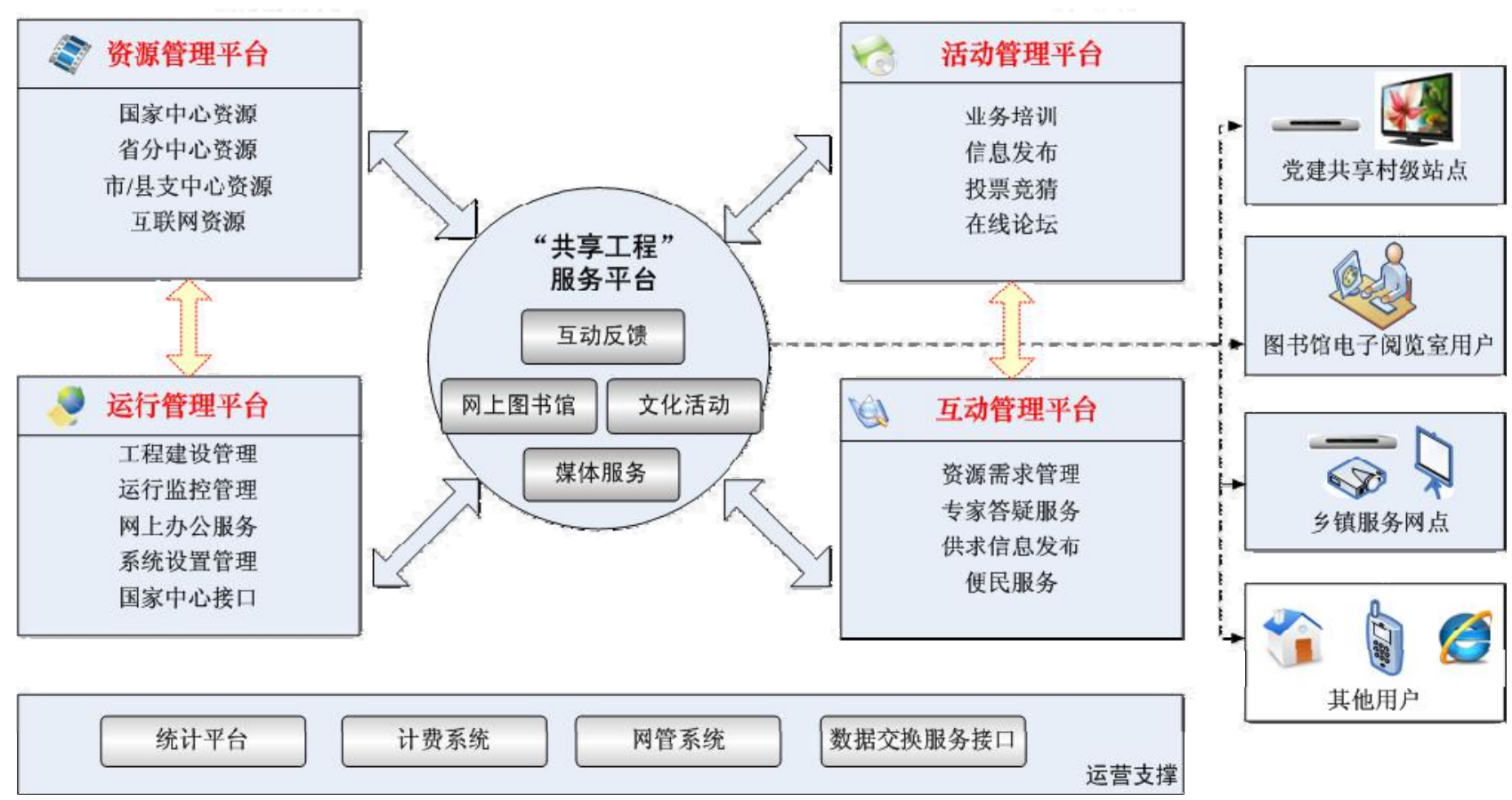

圖 2. 系統模塊組成圖

Figure 2. System modules

合、機構調整、資訊共用節約了大量的建設經費和維 護經費。

\section{2 易維護}

省分中心、縣支中心的資源存儲和視頻點播伺服 器都託管於聯通機房, 減少了工作人員的維護難度和 工作量; 終端機頂盒支援網路自動升級, 避免了後續 功能擴展的問題。

\section{3 實用性強}

具有卡拉 $\mathrm{OK}$ 、線上播放、離線播放等功能, 適 用於農村群眾組織室內或廣場搞文化、科技教育活動。

\section{4 支援運營}

平臺具有廣告等增值業務的支援能力, 可以實現 目前的互聯網運營和未來的 $3 \mathrm{G}$ 網路運營。

\section{5 功能擴展性強}

支援電視機、投影機、PC、手機等設備上展現數 位圖書館、數位博物館、網上書畫展等業務, 且可以 支援互動培訓和線上考試等功能。

\section{6. 業務創新}

\section{1 卡拉 $O K$ 功能}

為了農村群眾的業餘生活, 省分中心加工了一批 群眾喜聞樂見的卡拉 OK 資源和非物質文化遺產中的 一些優秀曲目, 基層群眾可以通過機頂盒實現點歌、 唱歌、原唱和伴唱自由切換, 活躍了農村的文化生活 也傳承和發揚了本省的特色文化。

\section{2 資源更新服務}

通過 IPTV 網路, 基層服務點實現了共用工程資 源的網路更新、線上播放和離線播放。

\section{3 片頭插入功能}

通過資源管理平臺設置, 機頂盒可首先會預下載 需要插播的視頻, 存儲於本地, 在節目正片播放前快 速進行片頭插播。

\section{4 虛擬數字圖書館}

在機頂盒+電視機構建一個虛擬的“圖書館”和虛 擬的讀書氛圍, 為用戶提供拓展的數位圖書館服務。 


\section{5 滾動字幕}

伺服器可以控制機頂盒滾動字幕播發內容, 播發 時間及播發次數, 通過該平臺可以為基層群眾提供重 要的農業預警類的即時資訊、政府相關公告和天氣預 報等公共服務資訊。

\section{6 手機移動播放}

用戶可以通過 $3 \mathrm{G}$ 手機點播文化資訊資源分享工 程的電影、電視劇、戲曲等豐富多彩的精彩視頻節目。

\section{7. 效益分析}

河南省文化共用工程的實施, 將開闢一條不受地 域、時間限制的㰾新的文化傳播管道, 將豐富的文化 資源以先進的傳播方式傳輸到廣大基層群眾, 尤其是 欠發達地區的農民群眾手中, 對於打破落後地區資訊 閉塞的狀況, 消除“數位鴻溝”, 提高廣大人民群眾的 科學文化素質, 加強基層精神文明建設, 促進經濟、 社會協調發展、區域協調發展、城鄉協調發展將起到 積極作用。主要體現在以下幾個方面:

1）提出解決中西部經濟欠發達地區文化資訊資 源分享工程開展過程中重建設、輕服務的難題的方 法, 保障了文化資訊資源分享工程的可持續發展。本 項目的研究成果可推廣、複製到全國其他省、市, 將 帶動、促進全國文化共用工程的建設, 引領建設方向, 為此將產生重大的經濟和社會效益。

2) 促進農村經濟文化發展, 保障了農民群眾的權 益。通過與工商等單位合作, 對假冒偽劣產品進行曝 光, 避免次品和過期產品危害群眾的利益。

3) 通過互惠互利, 雙贏的思路拓展了文化共用的 內涵。通過與萬村千鄉農家店工程、家電下鄉工程、 金牧陽光工程進行合作, 對一些產品品質好、市場信 譽高的企業進行宣傳, 對促進內需, 拉動河南省農村 市場經濟, 農村物流體系建設, 農村文化建設和社會 和諧等都具有很大的意義。

4) 通過多種管道為農村群眾提供大量的農村實 用技術、城鎮勞務資訊、農副商品產供銷資訊資源,
幫助群眾瞭解新技術、新產品, 開闢了農民發家致富 的新途徑。

5) 隨著 3G 的應用, 將可以帶動 1000 萬左右的 城鄉手機用戶享受到文化共用工程的服務, 有效的擴 展了文化共用工程資源的服務範圍。

6) 通過互聯互通, 數位圖書館建設打破原來的數 字鴻溝, 實現全省範圍內的“讀者共用”、“館員共用”、 “數位資源分享”和“網路共用”, 利用互聯網的傳遞和 交互功能, 把數位參考諮詢服務和各級圖書館的資訊 資源實現了有效的整合, 極大的改善公共圖書館、鄉 鎮村文化站的公共資訊服務能力, 全面提升、拓展城 鄉一體化公共文化服務體系及其事業主體的多元化服 務能力與社會效益。

\section{8. 結 論}

河南省文化資訊資源分享工程實施以來，始終堅 持廣開管道、合作共贏、科學規劃、拓展服務的建設 理念，不斷進行實踐和探索，結合全省公共文化體系 建設找到了一條適合河南省實際情況的建設模式，形 成了河南省文化資訊資源分享工程跨越式發展的長效 機制，找出文化資訊資源分享工程可持續發展的一條 新路子，取得了良好的服務效果。在豐富農村群眾精 神文化生活、發展地方經濟建設和縮小城鄉之間文化 發展差距發揮了重要作用。

\section{REFERENCES}

[1] 文化部關於做好 2008 年全國文化資訊資源分享工程建設工 作的通知文社圖發 [2008] 17 號 http://www.ccnt.gov.cn/ gsjpd/shwh/sttsggz/t20080624_55325.htm.

[2]全國文化資訊資源分享工程“十一五”規劃發展綱要 http://www.ccnt.gov.cn/gsjpd/shwh/sttsggz/t20061011_30821.htm

[3] 全國文化資訊資源分享工程情況 http://www.ccnt.gov.cn/gsjpd/ shwh/sttsggz/t20080305_52104.htm.

[4] 中共河南省委組織部、河南省黨員幹部現代遠端教育試點工 作領導協調小組、河南省文化廳、河南省財政廳. 關於加強 全省農村黨員幹部現代遠端教育與文化資訊資源分享工程資 源整合工作的通知. 豫組通[2007] 10 號.

[5] 全國文化資訊資源分享工程介紹 http://www.ndcnc.gov.cn/ libpage/gxgc/index.htm. 